Article

\title{
Business Model Innovation in News Media: Fostering New Relationships to Stimulate Support from Readers
}

\author{
Giuliander Carpes da Silva * and Gabriela Gruszynski Sanseverino \\ Laboratory of Studies in Applied Social Sciences (LERASS), University Toulouse III Paul Sabatier, 31330 Toulouse, France; \\ E-Mails: giuliander.carpes-da-silva@univ-tlse3.fr (G.C.d.S.), gabriela.gruszynski-sanseverino@univ-tlse3.fr (G.G.S.) \\ * Corresponding author
}

Submitted: 14 December 2019 | Accepted: 5 February 2020 | Published: 16 April 2020

\begin{abstract}
Customer relationships are an important pillar of a business model (Osterwalder \& Pigneur, 2010). For years, though, news media has not invested much effort into nurturing rich connections with their consumers and, consequently, neglected the promotion of a participatory culture that could bring benefits for all involved (Neuberger \& Nuernbergk, 2010; Rosen, 2006). Vanishing advertising revenue and changing habits of news consumption on the Internet create a situation for changing that situation-especially when considering journalism as a service (Jarvis, 2014). Therefore, this article employs multiple case-study research to analyze and compare how four digital news natives from different countries (The Correspondent from the Netherlands, eldiario.es from Spain, Mediapart from France, and the Brazilian branch of The Intercept) are creating more meaningful connections with their audiences in order to sustain their businesses. We found out that all cases resort in varying degrees to the ideology of journalism, personification, transparency, impactful content, and community as motivations to attract members, while at the same time refraining from advertising becomes a guarantee of independence. Social media is losing ground, as companies use their own platforms and channels, such as emails, to develop routines that take member participation into account in different levels-from intermediate to maximal-though customization is still limited. The challenge for online-born news companies is to manage so many variables while taking into consideration feedback from their sustainable base of members.
\end{abstract}

\section{Keywords}

business models; customer relationships; digital journalism; entrepreneurial journalism; innovation; news media; revenue sources

\section{Issue}

This article is part of the issue "Digital Native News Media: Trends and Challenges" edited by Ramón Salaverría (University of Navarra, Spain).

(C) 2020 by the authors; licensee Cogitatio (Lisbon, Portugal). This article is licensed under a Creative Commons Attribution 4.0 International License (CC BY).

\section{Introduction}

Advertisers spent around US\$ 330 billion on digital inventory in 2019, an increase of $17,6 \%$ in comparison to the previous year. Those numbers reflect a growing trend of the 2010s: The online advertising market exceeding television and print in several of the most important markets (Enberg, 2019). However, for news publishers, reaching much larger audiences than in the past does not exactly mean acquiring more financial gains. Hence, most of the media nowadays is looking at diversifying with, and regaining control over, other revenue sources-especially ones derived from readers (Rashidian, Tsiveriotis, \& Brown, 2019).

Online news consumption, though, made it more difficult for publishers to control the value chain of content production and distribution (van der Wurff, 2012). People can now choose to get the information they want from multiple sources, many of which are free. Therefore, the willingness to pay for news content in most countries is still low (Newman, Fletcher, Kalogeropoulos, \& Nielsen, 2019). In this sense, simply erecting paywalls 
around content may work for some well-established brands, but probably not for online-born news media, which need to innovate and develop relationships that create value for these readers in order to reach sustainability (Jarvis, 2014).

Eldiario.es (Spain), The Correspondent (Netherlands), The Intercept Brasil and Mediapart (France), all outlets that originated online and which we will study in this article, have proven themselves successful in using subscription/membership-based models to sustain their journalistic initiatives in a scenario where the traditional business strategies of journalism companies are often leading to difficulties. Thus, this research intends to answer: 'How are these news organizations developing new forms of relationships with readers in order to acquire sustainable revenues?'

To do so, we discuss what customer relationships are and the importance of business models for publishers, and what types of relationships arise between the consumer-audience and news companies. We also note manners used to attract the audience to digital news natives and reasons that incite the public to contribute to the journalistic enterprise.

\section{Theoretical Framework}

Journalism has played a vital role in society since the 19th century, when seeking information and reporting it to the public became its primary obligation (Kovach \& Rosenstiel, 2014), but the process of accelerated change driven by technology transformed the way it is produced, distributed, and used. Although we see the emergence of new tools and practices, we assume that there are non-negotiable and fundamental values that constitute the ideology of the profession, such as truth and accuracy, and, especially, a commitment to the public (Dahlgren, 2010; Hayes, Singer, \& Ceppos, 2007; Kovach \& Rosenstiel, 2014) - which also happens to be their consumer audience.

The newspaper industry is at a crossroads when it comes to reader engagement and interactive online platforms. While journalism remains surrounded by a professional ideology (Kovach \& Rosenstiel, 2014), media outlets are commercial enterprises that survive by attracting an audience. News companies are faced with challenges that derive from the failing of the traditional business model of the profession and an economic motivation for newspapers to move to the web. Understanding how to reach audiences, how to keep them, and how to thread each piece of journalism through a complex maze of different sites and applications has fundamentally changed the way newsrooms operate (Dahlgren, 2010; Hayes et al., 2007). Faced with changing media use, media companies need to innovate to remain profitable (McCluskey \& Hmielowski, 2011).

From a management perspective, customer relationships are essential to the value creation side of a business model: by developing them, companies are able to make a connection between their value propositions and their customer segments-and, eventually, acquire revenue from it (Osterwalder \& Pigneur, 2010). Due to its essence of public interest and importance to people's exercise of citizenship, Jarvis (2014) suggests journalism should also be understood as a service. In this sense, news companies would be able to solve real information needs for their readers and start developing closer relationships with them in order to keep improving the serviceand, consequently, find commercial opportunities derived from this connection. This approach to journalism can obviously generate criticism. It may be considered excessively attached to commercial interests or overly utilitarian, turning journalists into mere producers of content to satisfy people's basic interests-or curiosity-instead of contributing to needed civic discussions.

We understand there is a duality to the idea of journalism as a service. Beyond the notion of journalism as a public service (the function of providing the audience with credible information), journalism gained commercial value in the 19th century, with the institutionalization of journalistic culture, and the formation of a market for readers (Chalaby, 1996). At the same time, it also became a paid service provided by journalists to a consumer public. According to Carlson (2016), journalism varies constantly and continuously, taking many forms even simultaneously, depending on geographic and contextual factors, and is always subject to a set of social relationships and a dispute of forces from different fields.

In that sense, even imbued with a commercial logic, media companies can continue to fulfill their duty to the public with reliable information and, why not, be perceived as service providers to a consumer audience. As such, Skaggs and Youndt (2004) state that service companies keep basically three types of relationships with their customers: 1) 'Contact,' related to the amount of interaction a business keeps with the consumer; 2) 'co-production,' which refers to the smaller or bigger amount of effort-even creative-a customer should make in the production of the service; and 3) 'customization,' explained by the extent a company is able to personalize the offer for individual customers-by collecting, processing and analyzing data about their habits.

Journalism Studies usually gathers contact and coproduction in a single set of practices labeled as 'participatory journalism.' Participation in the process of news making is not new, but it became a widespread practice with the emergence of the Internet and social media (Singer, 2011). This situation represented a change in the power balance of news production and distribution since the audience became able not only to pitch news professionals with ideas and share their work on social media, but also question their points of view and even produce and disseminate their own news content (Rosen, 2006).

Traditional publishers, still dealing with the transition from print to digital, tend to struggle with this new reality (Neuberger \& Nuernbergk, 2010). Peters and Witschge (2015) point out that even outlets that employ a dis- 
course of participation, in fact, usually offer limited space for it. According to the authors, news organizations, in general, understand participatory journalism only as an opportunity to derive economic benefits while journalists still maintain a far higher hierarchical level on the relationship, keeping most of the control over the editorial processes. Therefore, participation generally tends to be minimal despite discourses of democratization and inclusivity (Table 1).

This situation opens room for digital news natives differentiation, which can be reached by the development of more meaningful and inclusive relationships, based on news consumers online habits, increasingly focused on deeper connections and greater exchange of information through person-to-person (journalist-toreader) interaction (Ingram, 2014). Even though Ingram's (2014) argument is based on anecdotal evidence, it does demonstrate that digital native news outlets have been more successful in implementing and seeing through participatory initiatives, whilst legacy news media struggle to sustain manners of public participation, as Porlezza (2019) shows.

In this sense, outlets are urged to adopt what Quamby, Goligoski, and Jenkins (2019) call 'memberful routines':

Normal ways of operating that incorporate members and produce value for a news organization, which is how they got to be routines in the first place. A simple example would be a database of members and their expertise that is routinely tapped to provide technical proofreading of articles and investigations. It might take time, but it also adds value. The value includes the added 'stickiness' of the member who is consulted about things that member knows a lot about. (p. 3)

These routines can have several formats: simple tools enabling members to vote on subjects of their interest, moderated comments sections, callouts where publish- ers ask for their expertise or interest on specific themes, structured surveys, real work with data shared that can be paid, participation on editorial and training events, etc. Interaction can work through different channels, such as the publishers' owned platforms, social media (Facebook Messenger and Groups are popular tools for that), emails-where different versions of newsletters can be tailored according to the interests and expertise of members subscribed-and even offline events and editorial meetings (Quamby et al., 2019). Participation is possible in the four steps of newsrooms' workflow: 1) planning; 2) research and reporting; 3 ) editing and factchecking; and 4) post-publication.

In order to develop this approach in journalism, there is a need to present attractive value propositions to users - or 'member motivations,' as Quamby et al. (2019) prefer to call them. The authors list mainly six reasons for readers to support news organizations: 1) learning something new; 2) contributing with expertise; 3 ) having a say and being heard; 4) finding out about the outlet's processes (transparency); 5) showing love for a mission that matters; and 6) being part of a community. Wagemans, Witschge, and Deuze (2016) mention that resorting to the ideology of traditional journalistic values can also be a compelling value proposition in times when traditional media faces a crisis of trust. A professional ideology is a set of principles shared by a group of people (Deuze, 2005). The ideology of journalism is supposedly formed by five main values: 1 ) Journalists provide a public service; 2) objectivity is essential and its consequence is credibility; 3 ) they are independent; 4) they have a sense of immediacy; and 5) they possess a sense of ethics and legitimacy (Deuze, 2005). We should note that we look at objectivity not as a lack of opinion, but as it relates to journalism's duty to truth, as the profession remains a space for reliable and credible news. Objectivity can be thought then as the balance of accuracy, which indicates the loyalty to what is factually indisputable, and fairness, that represents the pluralism of voices (Dahlgren, 2010).

Table 1. Scope and degree of participation.

\begin{tabular}{llll}
\hline Scope of participation & Minimal & Maximal \\
\hline $\begin{array}{llll}\text { Visibility and presence } \\
\text { of audience }\end{array}$ & $\begin{array}{l}\text { As respondents to } \\
\text { certain items only }\end{array}$ & $\begin{array}{l}\text { As authors of texts in } \\
\text { designated areas }\end{array}$ & $\begin{array}{l}\text { As structural contributors } \\
\text { throughout the platform }\end{array}$
\end{tabular}

Hierarchical level of interaction

Reply-based audience
response (i.e., polls),
detached from
journalistic interaction

Stage of production

Post-hoc, after news is presented as finished product
Interactions-based with other audience members and/or journalists, limited impact on production (i.e., audience photos, tweets for breaking news)

Real-time, during the (on-going) creation of a story
Dialogue and consultation-based input in news production at an editorial level

During the planning stages to co-design the news agenda, news angles and stories

Source: Peters and Witschge (2015). 
Wagemans et al. (2016) also call attention to a certain level of personification that can be employed by an outlet in order to attract support. It means news companies expressly take advantage of the reputation of its founders in order to convince readers to become members or subscribers.

Memberful routines and member motivations work not only as practices but as a philosophy digital news natives should adopt to improve the relationships with their readers-without a real commitment from the newsrooms, results tend to be less effective (Quamby et al., 2019). They can be employed basically by any publisher looking for reader revenue, either through memberships (when the publisher keeps the content free but asks for a donation from readers that can support their initiative), subscriptions (when content can only be accessed by paying subscribers), or other innovative models.

It is worth noting that the practices that involve public participation-especially contact-often go beyond journalism itself and can be performed, for example, with marketing intentions. Carlson (2016) observes that what he calls 'metajournalistic discourse' is not unusual and frequently works as a form of response from journalists to contention from forces outside the field:

A persistent thread (of research) shows how, in certain moments, journalists pivot from their role as producers of media discourse to become its object as well.... In connecting public discourse with the establishment of cultural meaning surrounding news, they show the need to look beyond news practices to explain journalism's cultural authority. (p. 4)

In this sense, these public expressions reflect on the relationships news companies and journalists have with their audiences and other forces that negotiate the boundaries of journalism with them, such as government officials, historians, and educators, among others:

Boundaries are powerful social constructions that affect the distribution of resources as well as the allotment of 'epistemic authority'.....Actors construct boundaries through metajournalistic discourse either directly through explicit categorization or implicitly through embedded assumptions in talk about journalism. (Carlson, 2016, p. 12)

Even though journalists can be considered the original proponents of these boundaries, they have no control over the result of this negotiation-the legitimation of their epistemic authority role is granted by their ability of convincing the other actors about the legitimate knowledge derived from the news they produce (Carlson, 2016). Once more, the importance of transparency is highlighted and reinforced within the process of establishing the boundaries of journalism and gaining legitimacy ahead of the other actors in this dispute. This value has not been contemplated by classic theory on the values of the profession and its adoption is not widely spread among legacy news outlets, while digital news natives are more open to it since their foundations-what exposes a clear advantage from them in establishing more hybrid forms of journalism and, consequently, closer relationships with their audiences (Hayes et al., 2007).

\section{Methodology}

This research is based on case studies of four digital news native companies from four different countries. The Correspondent is the English version of De Correspondent, created in the Netherlands in 2013 as "an antidote to the daily news grind" (The Correspondent, n.d.). The Dutch version raised more than $€ 1$ million in a crowdfunding round that turned 18,000 supporters into the first subscribers of the organization. In 2018, they launched another crowdfunding campaign that earned US\$ 2.6 million from 45,888 people at more than 130 countries in order to expand globally-which happened by the end of September 2019 (Pfauth, 2018). Eldiario.es, from Spain, was founded in 2012 by journalist Ignacio Escolar, former director of Público, together with professionals that had already worked with him. The founder and director is the main shareholder of the company, which is not attached to any big editorial group $-70 \%$ of its capital is formed by people from its newsroom. The outlet promotes advertising and counts on the support of members to "keep its independence" (eldiario.es, n.d.-a). The Intercept Brasil was funded in mid-2016 during the process of impeachment of the country's former president Dilma Rousseff. It was an opportunity found by co-founder and editor Glenn Greenwald-a Pulitzer Prize winner in 2014 for the revelation of National Security Agency's mass secret surveillance, who has lived in Brazil for a long timeto promote its recently created publication, originally funded by First Look Media, a philanthropic organization launched by Pierre Omidyar, the founder and chairman of eBay (The Intercept Brasil, n.d.-a). Mediapart is a French digital newspaper started by four former journalists of Le Monde and two technology specialists who raised a personal starting capital of $€ 1.325$ million and other $€ 1.614$ million from investors and a society of friends to launch in 2007-later, it received further investments (Plenel, 2008a). In October 2019, the company bought back all its shares and became a non-profit organization that receives and manages funds from almost 170,000 subscribers (Plenel, 2019).

First, we carried out a comprehensive documental and bibliographical research that entailed data from press releases, email newsletters, corporate reports, and articles published on the platforms owned by the outlets and also by specialized media. For example, we looked at news articles from The Correspondent's website "The Problem with Real News, and What We Can Do about It" (Wijnberg, 2019), “A Peek at the Correspondent's Launch Budget" (Anyangwe \& Pfauth, 2019) and "My Mission 
Table 2. Selection of cases.

\begin{tabular}{|c|c|c|c|c|c|}
\hline Publisher & Country & Business model & $\begin{array}{l}\text { Number of } \\
\text { members }\end{array}$ & Membership fee & Gross annual revenue \\
\hline The Correspondent & Netherlands & $\begin{array}{l}\text { Subscriptions } \\
\text { (hard paywall) }\end{array}$ & 50,000 & Choose what you pay & US\$ 2.6 million (2019) \\
\hline eldiario.es & Spain & $\begin{array}{l}\text { Advertising (60\%), } \\
\text { memberships (38\%) } \\
\text { and events ( } 2 \%)\end{array}$ & 35,000 & $\begin{array}{l}€ 7 \text { a month or } \\
€ 60 \text { a year }\end{array}$ & $€ 6.6$ million (2019) \\
\hline The Intercept Brasil & Brazil & $\begin{array}{l}\text { Philanthropic } \\
\text { foundation and } \\
\text { memberships }\end{array}$ & 9,000 & $€ 5,4$ to $€ 216$ a month & Non-disclosed \\
\hline Mediapart & France & $\begin{array}{l}\text { Subscriptions } \\
\text { (hard paywall) }\end{array}$ & 170,000 & $\begin{array}{l}€ 5 \text { to } € 15 \text { a month or } \\
€ 50 \text { to } € 150 \text { a year }\end{array}$ & $€ 13.8$ million (2018) \\
\hline
\end{tabular}

Note: * Approximate numbers based on company reports and/or interviews.

as Your Conversation Editor" (Shabbir, 2019), as well as their founder Rob Wijnberg's blog on Medium, that has several posts which debate policies and practices behind the news enterprise (Wijnberg, 2018a, 2018b, 2018c, 2018d).

Several sources were important for analyzing eldiario.es' relationships with readers and members. Founder and director Ignacio Escolar owns a blog where he publishes every six months a comprehensive report on the financial figures of the company (Escolar, 2019a, 2019b). The directors of the company have also given several interviews to blogs and specialized media (Nafría, 2018; SuscribeME suscripciones digitales, 2019), and eldiario.es also has a blog focused strictly on memberswhich highlights benefits such as lower prices for cultural events and debates with journalists from their newsroom (eldiario.es, n.d.-b).

We also investigated documents published by Mediapart director Edwy Plenel that describe the project of the enterprise (Plenel, 2007), their stance on free press (Plenel, 2008b), and the importance of independence for their organization (Plenel, 2008a); and looked at interviews he granted in which he spoke about the company, its purpose, and ideology (Grasser, 2019; Martinez, 2018; Rhian \& Foreau, 2019). Interestingly, email newsletters were some of the main sources of information for this research for the case of The Intercept Brasil. From November 5th, 2019, when we first subscribed to it, until December 15th, 2019, the day we submitted this article, they sent us 16 emails. The company has a strategy of frequently sending them signed by one of their journalists - the four examples signed by Leandro Demori, their executive editor, and the one signed by Marianna Araújo, their director of communication were of particular interest to this research (Supplementary File, Annex 1), since they show how the company employs metajournalistic discourse in order to directly address members and potential ones in order to present their views on their professional role.
In order to collect further information about the selected cases, we also looked at academic articles that focused on our studied cases, or that mentioned them as examples of journalistic practices (Canu \& Datchary, 2010; Guerrero, 2017; Masurier, 2015; Newman, Levy, \& Nielsen, 2015; Picard, 2014; Quamby et al., 2019; Thurman \& Myllylahti, 2009; Wagemans et al., 2016).

Following that, we ran a continuous and systematic platform observation between October 28th and November 3rd, 2019, on the companies' websites, mobile applications (in the case of eldiario.es and Mediapart), and main social media channels (Facebook, Twitter, and Instagram) in order to identify traces of the memberful routines mentioned by Quamby et al. (2019) and the metajournalistic discourse theory described by Carlson (2016). Every day during that week, we opened the article of the main headline of the website and apps of the publishers as well as other articles that could demonstrate a clear interest for membership reasonsfor instance, announcements of new corporate reports or events made available for members.

Both during the desk and platform research, we performed a content analysis of the collected material in order to find answers or at least hints for a set of 12 questions related to our theoretical framework (Supplementary File, Annex 3). Since the amount of material analyzed was comprehensive, this process already provided us with considerable insight into the strategies employed by the selected publications to maintain sustainable relationships with their public.

We still reached out to every outlet with requests for complementary information. A semi-structured questionnaire with around 10 questions (Supplementary File, Annex 2) was applied during interviews that lasted more than 40 minutes with María Ramírez, director of strategy at eldiario.es (via Skype); Marianna Araújo, communication director at The Intercept Brasil (via Google Meet); and Livia Garrigue, manager of Le Club, and Ana Ferrer, community manager at Mediapart (they received us per- 
sonally in Paris). Carmen Schaack, member support manager at The Correspondent, preferred to answer our questions via email.

\section{Findings and Discussion}

\subsection{Member Motivations}

All of our cases resort, in varying degrees, to the 'ideology of journalism' as a resource to attract members. Mediapart and eldiario.es are the ones who employ a more classical approach to it. Both cases clearly mention in their introductory pages most of the principles that describe this ideology, such as independence, sense of ethics, and the defense of democracy. Eldiario.es interestingly uses the slogan "periodismo a pesar de todo" ("journalism, despite of everything," authors' translation), which summarizes its value proposition for readers: a return to the profession's values as a way of defending its importance in times of lack of credibility and increasing pressure from political powers (eldiario.es, n.d.-a). Mediapart was created with the goal of practicing independent and participative journalism (Mediapart, n.d.): They are committed to the concept of the profession as public service (Plenel, 2007; Rhian \& Foreau, 2019). Their commitment to their readers is paralleled to the importance they give to their journalistic independence, proven by one of their slogans, which reads "only our readers can buy us." In the French media market, being a member-based company is how they innovate; not reimagining journalism, but returning to the traditional ideology of the profession, with values such as truth-telling, editorial autonomy, and independence (Wagemans et al., 2016).

The Correspondent and The Intercept Brasil attempt to show readers that they keep the main values of the profession while at the same time updating others. The Dutch publisher steps away from hard news and into slow journalism, rejecting the daily news cycle and having a different approach to immediacy, yet still promising relevant information for the public, claiming to respect what the audience wants from journalism today (Wijnberg, 2019). The Brazilian outlet, on the other hand, seeks to hold the powerful accountable through fearless and combative journalism with deep investigations and relentless analyses-a discourse that resonates with a purist ideology of the profession (The Intercept Brasil, n.d.-a). However, this is put in practice through a certain level of militancy and a clear political stance, which is clear in the email newsletters collected (Supplementary File, Annex 1) and admitted by the company's director of communication in her interview to us: "If there is no reader to buy in this ideology, buy your brand, ultimately (buy in) the whole combo Intercept, it is difficult to deal with the question of sustainability" (personal communication).

Since the values of the profession are so important for the cases analyzed, it is not surprising that most of them also use 'personification' as a selling point of their initiatives. Eldiario.es' founder and director, Ignacio Escolar, is personally in charge of publishing the company's reports to members-and, consequently, asking for more support-as well as answering their comments on these occasions (Escolar, 2019b). Director of strategy María Ramírez states that he also sends personal emails to each person that decides to quit their membership: "He's very present on TV and everything, he is a public figure. Definitely that helps....Definitely he is a big asset for the paper," says Ramírez (personal communication). A person with similar functions at Mediapart is Edwy Plenel, the organization's most recognized founder. He became the face and voice of the company, advocating for a return to serious and committed journalism in France, selling and defending Mediapart's ideology and brand of investigative journalism in the media market to its fellow news outlets, to academia and to the public itself (Grasser, 2019; Martinez, 2018; Rhian \& Foreau, 2019).

Glenn Greenwald's popularity has certainly increased in 2019 after The Intercept Brasil received from a whistleblower the files of conversations that prosecutors of Operation Car Wash exchanged with judge Sergio Moro before the condemnation of former Brazilian president Luiz Inacio Lula da Silva in a corruption case-he participated on several TV and radio programs to answer questions about the subject: "Glenn was a relevant public figure for the debate of world politics even before The Intercept Brasil existed. So, this is unstoppable.....It is natural that, in the search for references, the people associate the company to him," says Marianna Araújo (personal communication). Correspondent's founder Rob Wijnberg had made a name for himself in Dutch journalism before deciding to start the company, having been the youngest editor in chief of a national daily paper in Europe (Wallach, 2018). The founding of the organization in 2013 earned him the title of Journalist of the Year by the Dutch Association for Journalists (Wallach, 2018), and he has been vocal about his views of the profession (Medium, n.d.)

'Transparency' specifies the effort of making visible the production process of news as well as its limitations, and providing the public, which in membership sites is an essential part of the sustainability of the enterprise, with the behind the scenes of the company-how their money is spent, what resources journalists use, etc. In all of these accounts, transparency remains an essential value of journalism (Dahlgren, 2010), sustaining the company as it becomes an element to attract the audience and inspire their trust in the outlet (Hayes et al., 2007). Interestingly, the European cases from our sample not only try to keep members aware of their journalistic processes, but also periodically disclose numbers related to their financial sustainability-a behavior that apparently also collaborates in the process of enhancing their credibility, and even helps with acquiring new members, depending on the discourse used to explore the figures: "It makes current members proud and more involved, some- 
times they even raise their membership monthly fee. It is one of the key messages from eldiario.es since the very beginning," explains Ramírez (personal communication).

The Intercept Brasil is the only case of the sample that still does not disclose their whole financial figures - the number of people who became members and the amount collected is shown in a third-party website where the memberships are paid (Catarse, n.d.), but those numbers count even people who actually could not effectuate the payment due to any problem and they are not compared to the whole budget of the company. Director of communication, Araújo, alleges that they are already studying ways to make more transparent reports available to readers.

Three out of the four cases admitted that impactful content' has a direct relation to the growth of their base of members. Investigative journalism and the consequent release of exclusive news stories - the famous and traditional 'journalistic scoop'-brings notoriety to news outlets and proves to be a way to draw in new members. With over ten years in the French media market, Mediapart has broken some of France's biggest scandals involving politicians, such as the investigation that claimed Libyan dictator Muammar Gaddafi gave Nicolas Sarkozy $€ 50$ million for the 2007 presidential campaign (Willsher, 2018). At eldiario.es, in 2018, they published a series of investigative reports accusing the former president of the Madrid community, Cristina Cifuentes, of receiving a diploma in the Master in Autonomous Law at the Rey Juan Carlos University without participating in classes or receiving approval in some disciplines (Ejerique, 2018). The repercussion of the case forced her to resign and increased eldiario.es' base of members from 22,296 to 34,028 (growth of 52,6\%) in a single year (Escolar, 2019a). Something similar happened with The Intercept Brasil in 2019, during the abovementioned case in which the judge and prosecutors combined measures during the lawsuits of the largest anti-corruption operation in the history of the country. Before the series of reports, they were raising around $\mathrm{R} \$ 50,000$ per month, an amount that was increased to around $R \$ 250,000$ (a growth of basically 500\%) by the end of November, according to the communication director of the company, who points out, though, that content was only the trigger for that growth:

The Intercept Brasil was not part of the public conversation of the country because it was too small. Those stories allow the broader audience to know our work. This is one point. The Intercept Brasil also makes the usage of a language that allows greater proximity to the reader. We work a lot on that, and I think that was crucial for the success of our campaigns. (personal communication)

That sums up 'community,' a value proposition employed differently by all cases. The Correspondent and The Intercept Brasil consider themselves as 'movements' instead of normal news outlets because they count on members' support to spread their word and pressure authorities for 'change' (Supplementary File, Annex 1), while eldiario.es and Mediapart prefer to keep a more sober approach and maybe a less passionate relationship with their members, as we derive from interviews.

\subsection{Channels}

All of our cases make available for members or subscribers a space for participation in their 'owned platforms.' This space varies from a simple section for comments (all of them have it), to a whole section dedicated to content completely provided by members, which is the case of Mediapart's Le Club. Eldiario.es provides spaces where members can vote on polls and report mistakes to be corrected by their journalists in the articles.

'Emails' are a very popular channel for interaction with members as well. Eldiario.es and The Intercept Brasil make an email address available for readers to share information that can lead to news coverage on their websites (eldiario.es, n.d.-c; The Intercept Brasil, n.d.-b). The Correspondent also calls out for their members to contribute with stories and opinions, as well as criticism and suggestions via email, divulging the contact for their correspondents and for their public liaisons (Shabbir, 2019). Mediapart does not encourage collaboration for stories via email, but that is because they provide Le Club. Publishers seem more excited, though, by the engagement their email newsletters can produce. Beyond simple content distribution, they are using them in order to strengthen ties with members and reinforce their importance for the business models adopted. The Correspondent and The Intercept Brasil, for example, frequently employ them to start conversations with their members from the content they already published or to help them prepare upcoming news pieces.

Publishers still rely on 'social media' to reach readers, but third-party digital platforms are rarely a place of meaningful interaction beyond simply distribution. The Correspondent attempts to be an exception to that. They aim for quality over quantity when it comes to publishing content on their social media profiles, ensuring they can interact with the public in their posts. On Facebook and Instagram, we noted they published one or two stories a day and they made an effort to prompt public contribution in their comment sections, with a subsequent attempt to answer comments, engaging with their audience on all channels. On Twitter, while they produced more content tweeting links to their main stories of the day, they still tried to recognize public interaction with their profile, by liking audience tweets. It is a notable effort because they use social media not only as a form to distribute content and reach a larger audience, but to actually engage with the public. The Intercept Brasil holds frequent live streams on Instagram where their main journalists can talk about their last articles and answer questions from the audience. The non-profit or- 
ganization also keeps a private group on Facebook only for paying members where they try to make their journalists become conversation leaders by posting new content, making and answering questions, etc. The engagement, though, is limited and the company is still not satisfied with the results of this initiative.

The Correspondent, eldiario.es, and Mediapart hold 'offline events and editorial meetings' with members and non-members. The Dutch and Spanish publishers seem to be the ones who employ events as a more frequent channel, making their schedule available on owned platforms, social media and sending invites by email (eldiario.es, n.d.-b). According to Momkai, the design studio that helped The Correspondent to be launched, "empowering our community of members means bringing a digital concept into the physical world" (Momkai, n.d.).

\subsection{Relationships}

The channels cited above give a preview of the various forms of 'contact' and 'co-production' that are made available by the cases analyzed in this research for members or subscribers. The level of meaningful participation, though, varies significantly from case to case. In this sense, The Correspondent is considered to be the outlet from our sample that is more open to participation. They try to establish conversations in all channels they keep open for readers and attempt to profit from members' expertise basically in all steps of the workflow. Eldiario.es and The Intercept Brasil are less prone to accepting contributions during the two intermediary steps of the workflow, as María Ramírez explains:

We are kind of skeptical about news outlets that make-or say they make-readers work like The Correspondent and all these examples. Because, in the end, readers appreciate when you are useful to them, but I'm not sure they appreciate when you are chasing them and making them work. And, actually, our experience is that tips could come from anyone. Scoops, that's why you need journalists, to find them, right? (personal communication)

Mediapart is the only case from our sample to keep a specific space for member contributions, as mentioned before. At Le Club, subscribers can submit complete articles that eventually may be headlined on a sidebar of the publisher's homepage-more frequently, though, they are kept only at the page of the club. On the one hand, this can be understood as a good practice since it reserves a permanent space for users to collaborate. In this sense, it means allowing participation in all the steps of the workflow. On the other hand, though, it is clear that Mediapart makes a distinction from professional journalism and participation. Hence, there are actually two workflows happening in parallel and members are not really being allowed to participate in the process led by journalists.
If we consider contact to be the most basic relationship news companies can keep with their readers and an initial form of participation, we can conceive all selected cases have already gone through this first level and reached the point where they have a coproduction relationship with their members. Their levels of co-production, though, vary significantly. Eldiario.es and The Intercept Brasil keep co-production at an intermediate level, while Mediapart and The Correspondent employ it at a level closer to maximal, even though the French publisher practices a contradictory style of coproduction, as explained above.

We consider that applying to practice the scope and the degree of participation scheme suggested by Peters and Witschge (2015) is very difficult due to its excess of normativeness. We found variations of intensity inside each degree that make it complicated to have objective definitions. For example, we could consider that the hierarchical level of interaction at The Intercept Brasil is maximal because they allow "dialogue and consultationbased input in news production at an editorial level" (Peters \& Witschge, 2015, p. 26). Although, it is not clear that just by opening the channel they really take these consultations seriously into account when producing their content. It actually seemed more like a pro forma procedure than an effective collaboration.

'Customization' is actually a relationship that all selected cases can still improve. The highlight in this regard, once again, is The Correspondent, which allows members to follow specific journalists or collections of stories in a determined subject on the website, creating a personalized feed on a user's menu. One can also save their favorite stories and receive recommendations based on that choice. It is an interesting effort that uses the tools provided by digital media to create a modern website with features that can turn one's experience in their news site as personal as possible, which is aligned with their proposal of turning away from the general news cycle and embracing an innovative way to consume journalism, developing a relationship with the public based on their wants and needs. Eldiario.es allows users of its mobile application to follow subjects according to their interests. The Intercept Brasil and Mediapart do not provide any customization options on their platforms. Interestingly, though, all cases allow limited customization in their newsletters. In the case of eldiario.es and Mediapart, it is possible to actively select the emails a reader deserves to receive, while The Correspondent and The Intercept usually tailor their newsletters to readers' interests according to the subjects of previous ones they have already opened.

\section{Conclusion}

In this research, we discussed five valuable member motivations, four categories of channels and three variations of service relationships the selected cases employ in order to develop meaningful connections with their mem- 
bers. This shows how complex it is for digital news natives to establish the so-called memberful routines cited by Quamby et al. (2019) and how varied they can be. Even successful cases show significant differences, constantly reassessing their choices and make changes that take into consideration their philosophies, professional views, available resources and particularities related to the market in which they are positioned.

Being member-based journalistic companies is part of the four selected cases' brands. It is representative not only of their business models, but also an indicator of how they view their journalistic mission and what journalism they propose. The role of advertisement-or lack thereof-is relevant for their relationships with the audience. Being 'ad free' is, overall, a member privilege and a form to secure independent journalism, as they can consider themselves accountable to their paying members and no one else; just as their subscribers enjoy a space where they are free to navigate without the intrusion of advertisements. Having no or limited ads becomes a selling point, not only for providing a clean navigation of their news sites but because it emboldens their commitment to news as public service and to the journalistic value of independence.

We should note that even though these four companies have been proving successful in keeping themselves afloat and conducting their brand of journalism through member support, sustainability remains challenging. They have to make a continuous effort in the management of a meaningful relationship with their members, as well as regularly attempting to capture new subscribers. It is not clear, though, that simply allowing more participation is the correct path for that. Every publisher has to find its own dose, according to the assessment of their consumers' needs. Sometimes it is maximal, sometimes it is a little less. Keeping a stable-or growing, if possible-base of members and frequently collecting their feedback through the various channels available seems to be the most important metrics.

It should be considered that even though our analysis of the news companies' relationship with their members took into account an extensive review of documents and bibliography pertaining to their strategies and history, as well as interviews with representatives from the organizations, our observation of their platforms and social networks was limited to a strict period of time. We recognize that a longer period of study of their presence online might have yielded more insights regarding how they establish relationships with members. We must also stress that our analysis is based on the point of view of the journalistic enterprises and not from their subscribers. We assume members legitimate them as they continually pay for their services and guarantee the sustainability of their businesses. Applying other methods, however, such as surveys, that consider the outlook of the members, would be a valuable path for future research to investigate their views on the relationships they establish and choose to maintain with news companies.

\section{Acknowledgments}

The authors performed this research as part of the JOLT Project. This project has received funding from the European Union's Horizon 2020 research and innovation programme under the Marie Skłodowska-Curie grant agreement No. 765140.

\section{Conflict of Interests}

The authors declare no conflict of interests.

\section{Supplementary Material}

Supplementary material for this article is available online in the format provided by the authors (unedited).

\section{References}

Anyangwe, E., \& Pfauth, E.-J. (2019, September 30). A peek into The Correspondent's launch budget. The Correspondent. Retrieved from https:// thecorrespondent.com/31/a-peek-into-thecorrespondents-launch-budget/254249600$107362 \mathrm{bb}$

Canu, R., \& Datchary, C. (2010). Journalistes et lecteurscontributeurs sur Mediapart [Journalists and readercontributors on Mediapart]. Reseaux, 2010(2), 195-223.

Carlson, M. (2016). Metajournalistic discourse and the meanings of journalism: Definitional control, boundary work, and legitimation. Communication Theory, 26(4), 349-368. https://doi.org/10.1111/comt. 12088

Catarse. (n.d.). The Intercept Brasil. Catarse. Retrieved from https://www.catarse.me/users/958285-theintercept-brasil

Chalaby, J. K. (1996). Journalism as an Anglo-American invention: A comparison of the development of French and Anglo-American journalism, 1830s-1920s. European Journal of Communication, 11(3), 303-326. https://doi.org/10.1177/0267323196011003002

Dahlgren, P. (2010). Charting the evolution of journalism: The horizon of democracy. Media Studies, 1(1/2), 3-17.

Deuze, M. (2005). What is journalism? Professional identity and ideology of journalists reconsidered. Journalism, 6(4), 442-464. https://doi.org/10.1177/ 1464884905056815

Ejerique, R. (2018, March 21). Cristina Cifuentes obtuvo su título de máster en una universidad pública con notas falsificadas [Cristina Cifuentes obtained her master's degree at a public university with forged notes]. eldiario.es. Retrieved from https:// www.eldiario.es/sociedad/Cifuentes-obtenidopublico-falseando-asignaturas_0_752075026.html eldiario.es. (n.d.-a). Qué es eldiario.es [What is eldiario.es]. eldiario.es. Retrieved from https://www. 
eldiario.es/que_es

eldiario.es. (n.d.-b). El blog de los socios [Member's blog]. eldiario.es. Retrieved from https://www.eldiario.es/ socios

eldiario.es. (n.d.-c). Danos una pista [Give us a tip]. eldiario.es. Retrieved from https://eldiario.es/pistas

Enberg, J. (2019, March 28). Global digital ad spending 2019. EMarketer. Retrieved from https:// www.emarketer.com/content/global-digital-adspending-2019

Escolar, I. (2019a, June 6). El periodismo es un servicio público: Las cuentas de eldiario.es en 2018 [Journalism is a public service: Eldiario.es accounts in 2018]. Eldiario.es. Retrieved from https://www.eldiario.es/ escolar/periodismo-servicio-publico-cuentaseldiarioes_6_907169284.html

Escolar, I. (2019b, October 28). Te necesitamos más que nunca: Las cuentas de eldiario.es en el primer semestre de 2019 [We need you more than ever: Eldiario.es accounts in the first half of 2019]. Eldiario.es. Retrieved from https://www.eldiario.es/ escolar/necesitamos-cuentas-eldiarioes-primersemestre_6_957564289.html

Grasser, F. (2019, March 31). [Interview] Edwy Plenel: "Nous sommes au service de l'intérêt public» [[Interview] Edwy Plenel: "We serve the public interest"]. Le Quotidien. Retrieved from https:// www.lequotidien.lu/a-la-une/interview-edwyplenel-nous-sommes-au-service-de-linteret-public

Guerrero, M. J. H. (2017). Translation in new independent online media: The case of Mediapart. Perspectives, 25(2), 294-307. https://doi.org/10.1080/ 0907676X.2016.1213304

Hayes, A. S., Singer, J. B., \& Ceppos, J. (2007). Shifting roles, enduring values: The credible journalist in a digital age. Journal of Mass Media Ethics, 22(4), 262-279. https://doi.org/10.1080/0890052070158 3545

Ingram, M. (2014). For journalists, interacting with readers isn't just good practice: It could mean survival. GigaOm. Retrieved from https://gigaom.com/2014/ 04/25/for-journalists-interacting-with-readers-isntjust-good-practice-it-could-mean-survival

Jarvis, J. (2014). Geeks bearing gifts: Imagining new futures for news. New York, NY: CUNY Journalism Press.

Kovach, B., \& Rosenstiel, T. (2014). The elements of journalism: What newspeople should know and the public should expect (3rd ed.). New York, NY: Three Rivers Press.

Martinez, F. (2018, April 20). Edwy Plenel, I'interview pour les 10 ans de Médiapart [Edwy Plenel, interview for 10 years of Mediapart]. Propos. Retrieved from https://mag.proposscpo.fr/2018/04/20/mediapartplenel-interview

Masurier, M. L. (2015). What is slow journalism? Journalism Practice, 9(2), 138-152. https://doi.org/10.1080/ 17512786.2014.916471

McCluskey, M., \& Hmielowski, J. (2011). Opinion ex- pression during social conflict: Comparing online reader comments and letters to the editor: Journalism, 13(3), 303-319. https://doi.org/10.1177/ 1464884911421696

Mediapart. (n.d.). Qui sommes-nous? [Who are we?] Mediapart. Retrieved from https://www.mediapart.fr/ qui-sommes-nous

Medium. (n.d.). Rob Wijnberg. Medium. Retrieved from https://medium.com/@robwijnberg

Momkai. (n.d.). Creating events where an online community meets in person. Momkai. Retrieved from https://www.momkai.com/cases/decorrespondent_ events

Nafría, I. (2018, August 19). Entrevista a Ignacio Escolar, director de eldiario.es, medio español [Interview with Ignacio Escolar, director of eldiario.es, Spanish outlet]. SembraMedia. Retrieved from https://www. sembramedia.org/entrevista-ignacio-escolar

Neuberger, C., \& Nuernbergk, C. (2010). Competition, complementarity or integration? Journalism Practice, 4(3), 319-332. https://doi.org/10.1080/ 17512781003642923

Newman, N., Fletcher, R., Kalogeropoulos, A., \& Nielsen, R. K. (2019). Reuters institute digital news report 2019 (p. 156). Oxford: Reuters Institute for the Study of Journalism. Retrieved from https:// reutersinstitute.politics.ox.ac.uk/sites/default/files/ inline-files/DNR_2019_FINAL.pdf

Newman, N., Levy, D. a. L., \& Nielsen, R. K. (2015). Reuters institute digital news report 2015: Tracking the future of news. Oxford: Reuters Institute for the Study of Journalism. https://ora.ox.ac.uk/objects/ uuid:c1ecce4c-e829-4042-9693-84b524bf74ce

Osterwalder, A., \& Pigneur, Y. (2010). Business model generation: A handbook for visionaries, game changers, and challengers. Hoboken, NJ: John Wiley \& Sons.

Peters, C., \& Witschge, T. (2015). From grand narratives of democracy to small expectations of participation. Journalism Practice, 9(1), 19-34. https://doi.org/ 10.1080/17512786.2014.928455

Pfauth, E.-J. (2018, December 18). The Correspondent concludes crowdfunding campaign and raises $\$ 2.6$ million. Medium. Retrieved from https:// medium.com/de-correspondent/the-correspondenthits-its-crowdfunding-goal-of-2-5m-1fc6a1597fb1

Picard, R. G. (2014). Twilight or new dawn of journalism? Digital Journalism, 2(3), 273-283. https://doi.org/ 10.1080/21670811.2014.895531

Plenel, E. (2007). Le projet Mediapart [The Mediapart project]. Paris: Mediapart. Retrieved from https:// static.mediapart.fr/files/u1/Le_Projet.pdf

Plenel, E. (2008a, March 16). Comment Mediapart a construit son indépendance [How Mediapart builds its independence]. Mediapart. Retrieved from https://www.mediapart.fr/journal/france/090308/ comment-mediapart-construit-son-independance

Plenel, E. (2008b, March 16). Le prix de la liberté 
[The price of freedom]. Mediapart. Retrieved from https://www.mediapart.fr/journal/france/100308/ le-prix-de-la-liberte

Plenel, E. (2019, October 15). Mediapart no longer has shareholders. Mediapart. Retrieved from https://blogs.mediapart.fr/edwy-plenel/blog/ 151019/mediapart-no-longer-has-shareholders

Porlezza, C. (2019). From participatory culture to participatory fatigue: The problem with the public. Social Media + Society, 5(3). https://doi.org/10.1177/ 2056305119856684

Quamby, K., Goligoski, E., \& Jenkins, J. (2019). Making journalism more memberful (p. 61). New York, NY: The Membership Puzzle Project. Retrieved from https://static1.squarespace.com/static/58cfa917d2 b85767b5778f0a/t/5d6639e23295f200016c45c3/ 1566980612512/mpp_memberful_routines_ report_eng_01.pdf

Rashidian, N., Tsiveriotis, G., \& Brown, P. (2019). Platforms and publishers: The end of an era. New York, NY: Tow Center for Digital Journalism. Retrieved from https://www.cjr.org/tow_center_reports/ platforms-and-publishers-end-of-an-era.php

Rhian, \& Foreau, X. (2019, March 11). Interview with Edwy Plenel on: Freedom of the press, journalism and the Yellow Vests. Pressenza. Retrieved from https://www.pressenza.com/2019/03/ interview-with-edwy-plenel-on-freedom-of-thepress-journalism-and-the-yellow-vests

Rosen, J. (2006, June 27). The people formerly known as the audience. PRESSthink. Retrieved from http:// archive.pressthink.org/2006/06/27/ppl_frmr.html

Shabbir, N. (2019, October 2). My mission as your conversation editor: Doing journalism with you, not just for you. The Correspondent. Retrieved from https://thecorrespondent.com/50/my-mission-asyour-conversation-editor-doing-journalism-withyou-not-just-for-you/6619588250-64eb7de9

Singer, J. B. (2011). Journalism in a network. In M. Deuze (Ed.), Managing media work (pp. 103-109). Newcastle: Sage.

Skaggs, B. C., \& Youndt, M. (2004). Strategic positioning, human capital, and performance in service organizations: A customer interaction approach. Strategic Management Journal, 25(1), 85-99. https://doi.org/ 10.1002/smj.365

SuscribeME suscripciones digitales. (2019, June 21). María Ramírez (eldiario.es): "Nos gustaría que la mitad de los ingresos vinieran de los socios." [María Ramírez (eldiario.es): "We would like half of the income to come from the partners."] [Video File]. Retrieved from https://www.youtube.com/watch?v= tlyl58IC2rE

The Correspondent. (n.d.). About us. The Correspondent. Retrieved from https://thecorrespondent.com/ about
The Intercept Brasil. (n.d.-a). Entre em contato [Get in touch]. The Intercept Brasil. Retrieved from https:// theintercept.com/brasil/staff

The Intercept Brasil. (n.d.-b). O Intercept Brasil quer receber suas denúncias [Intercept Brasil wants to receive your tips]. The Intercept Brasil. Retrieved from https://theintercept.com/brasil/fontes

Thurman, N., \& Myllylahti, M. (2009). Taking the paper out of news. Journalism Studies, 10(5), 691-708. https://doi.org/10.1080/14616700902812959

van der Wurff, R. (2012). The economics of online journalism. In E. Siapera \& A. Veglis (Eds.), The handbook of global online journalism (pp. 231-250). Hoboken, NJ: John Wiley \& Sons. https://doi.org/10.1002/ 9781118313978.ch13

Wagemans, A., Witschge, T., \& Deuze, M. (2016). Ideology as resource in entrepreneurial journalism. Journalism Practice, 10(2), 160-177. https://doi.org/ 10.1080/17512786.2015.1124732

Wallach, E. (2018, November 23). An interview with Rob Wijnberg, co-founder of The Correspondent. The Politic. Retrieved from https://thepolitic.org/ an-interview-with-rob-wijnberg-co-founder-of-thecorrespondent

Wijnberg, R. (2018a, November 14). Why we let you decide your own membership fee at The Correspondent. Medium. Retrieved from https://medium. com/de-correspondent/why-we-let-you-decideyour-own-membership-fee-at-the-correspondent57ad4cb45ab1

Wijnberg, R. (2018b, November 30). Everyone is saying membership is the future of journalism. Here's how you can put it into practice. Medium. Retrieved from https://medium.com/de-correspondent/puttingmembership-into-practice-2e980c025fc9

Wijnberg, R. (2018c, November 30). Why The Correspondent is founded on the idea of progress. Medium. Retrieved from https://medium.com/decorrespondent/why-the-correspondent-is-foundedon-the-idea-of-progress-454eac725909

Wijnberg, R. (2018d, November 30). Why we want our journalists to take a stance at The Correspondent. Medium. Retrieved from https://medium.com/decorrespondent/why-we-want-our-journalists-totake-a-stance-at-the-correspondent-2486606e $54 \mathrm{f} 8$

Wijnberg, R. (2019, September 30). The problem with real news, and what we can do about it. The Correspondent. Retrieved from https://thecorrespondent. $\mathrm{com} / 22 /$ the-problem-with-real-news-and-what-wecan-do-about-it/513394530-b84c1be3

Willsher, K. (2018, March 16). How pioneering Mediapart has set the French news agenda. The Guardian. Retrieved from https://www.theguardian.com/ world/2018/mar/16/how-pioneering-mediaparthas-set-the-french-news-agenda 


\section{About the Authors}

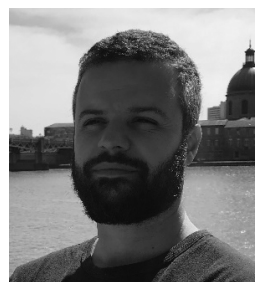

Giuliander Carpes da Silva is a PhD Candidate in Communication and Information Sciences at the Laboratory of Studies in Applied Social Sciences at the University of Toulouse III Paul Sabatier within the JOLT Project, a Marie Skłodowska-Curie European Training Network funded by the European Commission's Horizon 2020 initiative. Since 2014, he has been researching the effects of the platformization of the Internet on news media. In 2015, he completed a MA in Media \& Business at the Erasmus University Rotterdam.

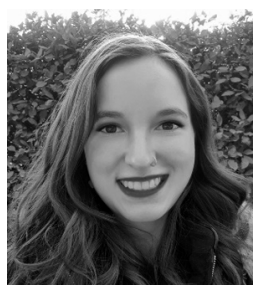

Gabriela Gruszynski Sanseverino is a PhD Candidate in Communication and Information Sciences at the Laboratory of Studies in Applied Social Sciences at the University of Toulouse III Paul Sabatier as part of the JOLT Project, a Marie Skłodowska-Curie European Training Network funded by the European Commission's Horizon 2020 initiative. She has a BA in Social Communication-Journalism, and a MA in Communication and Information from the Federal University of Rio Grande do Sul (Brazil). 